\title{
SYNTHESIS AND CYTOTOXIC EVALUATION OF NOVEL AZA INDOLE DERIVATIVES
}

\author{
Rajashekar Vadlakonda ${ }^{1 *}$, Raghunandan Nerella $^{2}$ and S. Vijaya Srinivas ${ }^{3}$ \\ ${ }^{1}$ Pharmaceutical Chemistry, Vikas College of Pharmacy, Jangaon-506 167, Telangana, India. \\ ${ }^{2}$ Pharmaceutical Chemistry, Balaji Institute of Pharmaceutical Sciences, Narsampet, \\ Warangal-506 331, Telangana, India. \\ ${ }^{3}$ Pharmaceutics, Vikas College of Pharmacy, Jangaon - 506 167, Telangana, India. \\ *E-mail: rajashekar4you@gmail.com
}

\begin{abstract}
Azaindoles are an important class of nitrogen-containing heterocyclics and were identified as the most active and potent classes of compounds with a wide range of biological and pharmacological activities. They were extensively used as pharmaceuticals. Although the number of drugs is available in the market even though the search for new molecules is ever demanding. In present work, various Azaindoles were synthesized and characterized using physical and spectral data. Finally, the Azaindole derivatives were screened for their In vitro cytotoxic activity. Some of the molecules exhibited very good potency when compared with respective standards. The approach is very challenging and was found difficult to get a molecule with potency. Even though, the present molecules were provided novel leads against Cancer and also insights into structural features required to be considered while designing the molecules with Azaindole core structures for cytotoxic studies.
\end{abstract}

Keywords: Azaindoles, heterocyclics, potent, cancer, cytotoxic.

(C) RASĀYAN. All rights reserved

\section{INTRODUCTION}

Cancer is one of the dangerous diseases in which cells are invasive i.e., invade and destroy adjacent tissues and are metastasize to other parts of the human body. These malignant properties of cancer cells such as invasive and metastatic nature of cancers differentiate cancers from benign tumors. Benign tumors have limited course in their growth and these do not invasive or metastasize. But some benign tumors are capable of being infectious. Cancer can affect people of all ages. But cancer is a disease which causes the chances of getting infected with an increase in age. Cancer can be caused by both external factors like tobacco chewing, through infectious organisms, because of chemicals and also due to radiation effects and internal factors which include inherited mutations, hormonal imbalance, suppressed immune conditions and due to mutations that occur through metabolism. These factors may act together or these can act in sequence to initiate and promote the chances to getting infected with cancer. ${ }^{1,2}$

Cancer is usually classified according to the tissue from which the cancerous cell originates, as well as the normal cell type they most resemble. A definite diagnosis usually requires the histological examination of a tissue biopsy specimen by a pathologist, although the initial indication of malignancy can be symptoms or radiographic imaging abnormalities. As research is developing day by day, treatment for cancer is becoming more specific for different types of cancer. There is noteworthy progress in the development of targeted therapy chemical agents that can act specifically and selectively on different molecular abnormalities in certain tumors thereby decreasing damage to normal cells.,

Indole is an aromatic heterocyclic organic compound. It has a bicyclic structure, consisting of a sixmembered benzene ring fused to a five-membered nitrogen-containing pyrrole ring. Indole is a popular component of fragrances and the precursor to many pharmaceuticals. Compounds that contain an indole ring are called indoles. Indoles are probably the most widely distributed heterocyclic compounds in nature.

Rasayan J. Chem., 10(4), 1316-1322(2017)

http://dx.doi.org/10.7324/RJC.2017.1041914 
Tryptophan is an essential amino acid and as such is a constituent of most proteins; it also serves as a biosynthetic precursor for a wide variety of tryptamine-, a neurotransmitter- 5-HydroxyTryptamine (serotonin) indole-, and 2,3-dihydroindole-containing secondary metabolites. Substituted indoles, azaindole group was considered as a potential surrogate for the indole core, thus providing a distinct series of therapeutic agents with varied pharmacological activities. The (mono)-azaindoles, trivially named pyrrolopyridines, where a carbon of the six-membered ring has been replaced by nitrogen either at 4- or 7-positions, are of theoretical interest as prototypes of bicyclic systems comprising an electron-rich ring fused to an electron poor ring. The simple systems do not occur in nature, but polycyclic compounds, such as the variolins have been isolated from sponges. Simple azaindoles have been isolated from coal tar and the oxidative degradation of carboline alkaloids. They have elicited significant interest in medicinal chemistry as isosteres of indoles, Azaindoles show the typical reactivity of both component systems but to a reduced and varying degree, with reduced electron density in the five-membered ring and increased electron density in the six-membered ring particularly as components of azatryptamine analogs and even as di-deazapurines.

Azaindole derivatives are under investigation as potential narcotic agonists, PPARy modulators, antitumor, antiparasitic, cytotoxic, selective B-Raf inhibitors, DP1 receptor antagonists, selective ATPcompetitive inhibitors of mammalian target of rapamycin (mTOR) etc. In view of the biological significance of azaindole moiety, it is yet to be explored synthetically and biologically with several other important heterocyclic systems.

Azaindoles have fueled considerable synthetic interest due to their physicochemical and pharmacological properties primarily as a bioisostere of purine or indole moiety. Substitution of the C-7 position of indole by $\mathrm{sp}^{2}$-hybridized nitrogen provides a skeleton containing a hydrogen-bond donor and acceptor in a rigid three-atom arrangement. Although naturally occurring 7-azaindoles are relatively scarce compared to indoles, 7-azaindole (1H-pyrrolo[2,3-b]pyridine) nucleus is present only in a few natural products such as alkaloids from the variolin family.

\section{EXPERIMENTAL}

General Procedure for the Synthesis of 1H-pyrrolo[2, 3-b]pyridino-3-carbonyl chloride (II); $[\text { Scheme-1] }]^{5,6}$

4.0 grams of 1H-pyrrolo[2,3-b]pyridino-3-carboxylic acid (I) was dissolved in 70ml of chloroform in an RB flask with stirring. Thionyl chloride $(4.03 \mathrm{ml})$ was added to the reaction mixture at room temperature in a dropwise manner. Reflux the reaction mixture for three hours. Cool the reaction mixture and distilling off the excess Thionyl chloride, 1H-pyrrolo[2,3-b]pyridine-3-carbonyl chloride (II).

General Procedure for the Synthesis of para-substituted 2(1H-pyrrolo[2,3-b]pyridine-3-carbonylN(p-tolyl)hydrazine carbothioamide) (III)

The cyclocondensation reaction of compounds (II) with para-substituted aryl thiosemicarbazide was carried out in a molar ratio of $1: 1$, using pure methanol as solvent. The reactions were monitored by TLC and the most satisfactory reaction time and reaction temperature were found to be $24 \mathrm{~h}$ at $20-25^{\circ} \mathrm{C}$.

\section{Synthesis and characterization of p-Substituted-2-[1H-pyrrolo]- [2,3-b]-pyridine-3-carbonyl]-N-[p- tolyl]hydrazine carbothioamides[Scheme-1; Route A; III $]^{9}$}

The synthesis of new title compounds has been carried out as per Scheme I (Route A). The synthesis has been affected by the reaction of 1H-pyrrolo[2,3-b]pyridine-3-carboxylic acid [I] in chloroform with thionyl chloride under reaction conditions yielded 1H-pyrrolo[2,3-b]pyridine-3-carbonyl chloride [II]. 1H-pyrrolo[2,3-b]pyridine-3-carbonyl chloride [II] undergo cyclocondensation with para-substituted aryl thiosemicarbazides in methanol yielded para substituted 2-(1H-pyrrolo)[2,3-b]pyridine-3-carbonyl-N-(ptolyl)hydrazinecarbothioamide [III a-e]. The progress of the reaction at every stage has been monitored by TLC. The usual workup of the reaction mixture has resulted in a single product. This product has been purified from aqueous ethanol to get a crystalline compound. The purified products have been subjected to spectral and elemental analysis for the purpose of their identification or characterization. As a model, one of the reaction has been presented. 
For illustration purpose, a similar reaction of 1H-pyrrolo[2,3-b]pyridine-3-carbonylchloride [II] has been subjected to cyclocondensation reaction with P-chlorophenylthiosemicarbazide using methanol as a solvent, yielded N-(4-chlorophenyl)-2-(1H-Pyrrolo[2,3-b]pyridine-3-yl carbonyl) hydrazine carbothiamide [IIIb].

The usual workup of the reaction mixture has resulted in a single product. This product has been purified from aqueous ethanol to get a colorless crystalline solid with a yield $85 \%$ and m.p. $220-225^{\circ} \mathrm{C}$.

Infrared Spectrum $\left(\mathrm{KBr}, \mathrm{Cm}^{-1}\right)$ has been found to show the following absorptions:

3310 (NH, str), 2932 (Ar-CH, str),

1685 ( $\mathrm{C}=0 \mathrm{str}), 1685$ and $1570(\mathrm{Ar}-\mathrm{C}=\mathrm{C}$ str $)$,

720 (C-Cl str).

${ }^{1} \mathbf{H}$ NMR Spectrum of the compound [in $\mathrm{CDCl}_{3}, 300 \mathrm{MHz}$ ] revealed the following characteristic proton signals $(\delta, \mathrm{ppm}): 3.85$ (br, s, $1 \mathrm{H}, \mathrm{NH}$ of ring), 4.06 (br, s, 2H, NH-S-NH),

6.32(s, $1 \mathrm{H}=\mathrm{CH}), 7.35-7.78(\mathrm{~m}, 7 \mathrm{H}, \mathrm{Ar}-\mathrm{H}), 8.05(\mathrm{~s}, \mathrm{br}, \mathrm{lH}, \mathrm{NH}-\mathrm{C}=0)$

Mass Spectrum (ESI, Positive) of the compound has recorded it's molecular ion : $\left[\mathrm{M}^{+}\right] \mathrm{at} \mathrm{m} / \mathrm{z} 345$ equal to its mass (Mol.Wt).

CHN analyses Calcd. for $\mathrm{C}_{15} \mathrm{H}_{12} \mathrm{ClN}_{5} \mathrm{OS}$ : C, 57.86; H, 4.21; N, 22.49; Found C, 57.82; H, 4.11; N, 21.98.

Based on the data recorded, the resultant compound has been characterized as $\mathrm{N}$-(4-chlorophenyl)-2-(1Hpyrrolo[2,3-b]pyridine-3-yl carbonyl) hydrazine carbothioamide [IIIb]

Five different azaindoles (IIIa-e) were synthesized and characterized.

Synthesis of $\mathrm{Z}-\left(\mathrm{N}^{1}\right.$-benzylidene-1H-pyrrolo-[2,3-b]pyridine-3- carbohydrazides [Scheme-1; Route B; $\left.\mathbf{V}_{\text {a-i }}\right]^{7,8}$

The synthesis of title compounds has been effected from 1H-pyrrolo [2,3-b]pyridine-3-carboxylic acid as depicted in Scheme-1.

1H-pyrrolo[2,3-b]pyridine-3-carbonyl chloride (II) has been obtained by stirring with thionyl chloride in chloroform under reaction conditions. The product thus obtained has been recrystallized from aqueous ethanol to get a colorless crystalline solid. The resultant compound (II) upon reflux with hydrazine hydrate in absolute alcohol yielded 1H-pyrrolo[2,3-b]pyridine-3-carbohydrazide (IV). The resultant product has been obtained by usual workup of the reaction mixture which has resulted in a single product. This product has been purified from aqueous ethanol to get a colorless crystalline solid with a yield $80 \%$ and m.p. $190-192^{\circ} \mathrm{C}$.

Its IR Spectrum $\left(\mathrm{KBr}, \mathrm{Cm}^{-1}\right)$ showed characteristic absorptions at $1690(\mathrm{C}=0$, amide $), 1670(\mathrm{C}=0$, pyrrolo-pyridine) and $1600(\mathrm{C}=\mathrm{N})$.

The PMR spectrum $\left(\mathrm{CDCl}_{3}, \delta \mathrm{ppm}\right)$ of the compound showed signals at 3.87 , (br, s, $\mathrm{IH}, \mathrm{NH}$ of the ring ) $4.80\left(\mathrm{br}, 2 \mathrm{H},,-\mathrm{NH}_{2}\right), 9.51$ (br, $\left.\mathrm{IH}, \mathrm{O}=\mathrm{C}-\mathrm{NH}\right)$.

Mass spectrum (ESI, positive) of the compound has recorded its molecular ion $\left[\mathrm{M}^{+}\right]$at $\mathrm{m} / \mathrm{z} 180$ equal to its mass (Mol.Wt).

CHN analyses Calcd, for $\mathrm{C}_{8} \mathrm{H}_{5} \mathrm{ClN}_{2} \mathrm{O}$

C, 53.21, H, 2.79, N, 15.51; Found: C, 53.19 H, 2.71 N,15.49.

Based on the analytical and spectral data recorded, the compound could be characterized as $1 \mathrm{H}-$ pyrrolo[2,3-b]pyridine-3-carbonyl hydrazine (IV). 
RASĀYAN J. Chem.

Vol. 10 | No. 4 |1316-1322 | October - December | 2017

1H-pyrrolo[2,3-b]pyridine-3-carbonyl hydrazide (IV) has been condensed with each of eight differently substituted aromatic aldehydes in the presence of alcohol to give a colorless fluffy solid. It has been purified by recrystallization from alcohol. The progress of the reaction at each stage can be monitored by TLC.

IR Spectrum $\left(\mathrm{KBr}, \mathrm{Cm}^{-1}\right)$ of the compound showed absorptions at $3340(-\mathrm{NH}$, amide); 1670(C=0 of pyrrolo-pyridine and amide), $1600(\mathrm{C}=\mathrm{N})$.<smiles>O=C(O)c1c(Cl)sc2[nH]cc(Cl)c12</smiles>

$1 H$-[2,3-b]pyridine-3-carboxylic acid $\quad 1 H$-pyrrolo[2,3-b]pyridine-3-carbonyl chloride

I

II

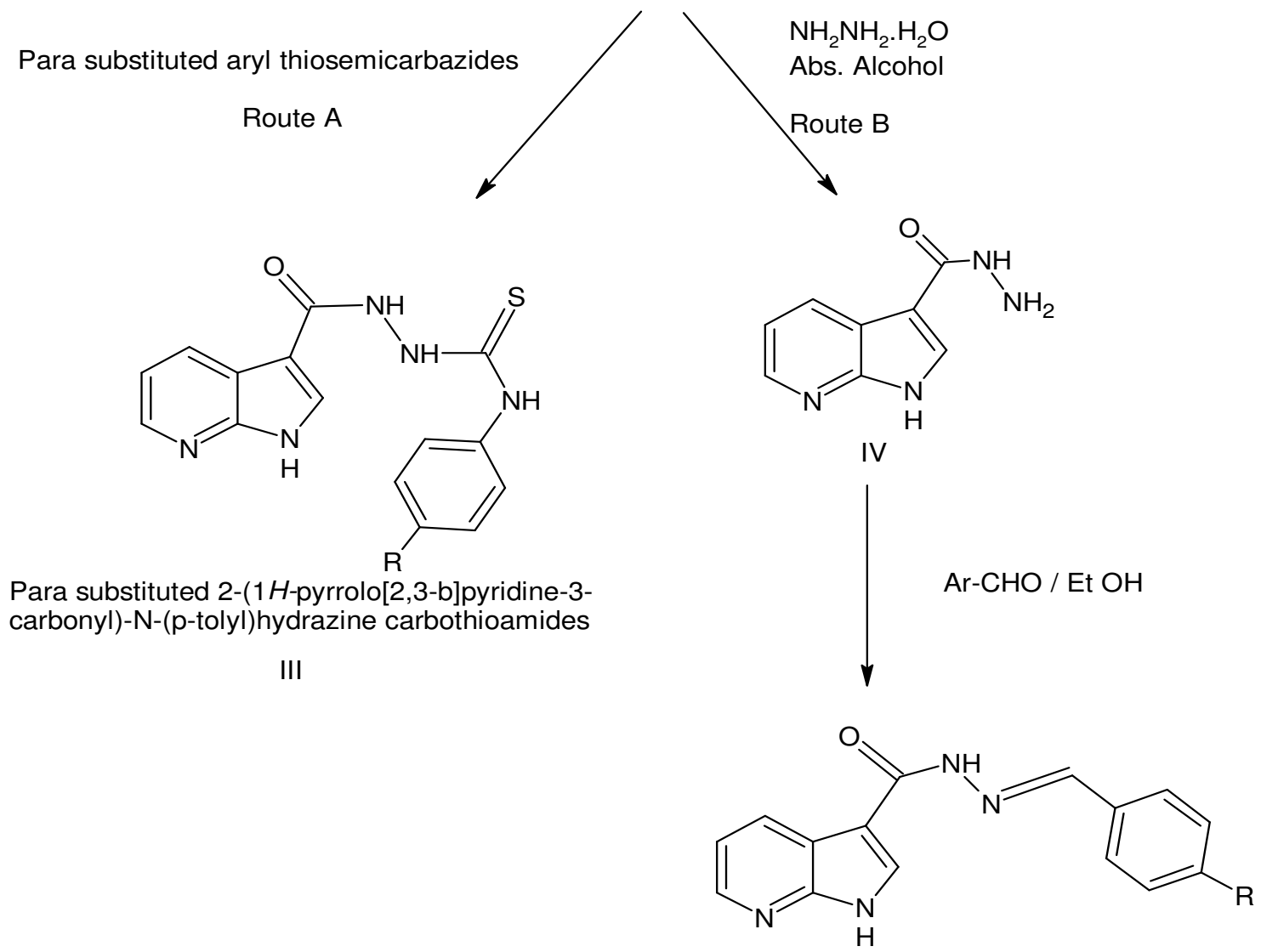

Para substituted (Z)-N-benzylidine-1 $H$-pyrrolo[2,3-b]pyridine-3-carbohydrazide

$\mathrm{V}$

Scheme-1

To present one of such reactions, in specific and in detail, a mixture of 1H-pyrrolo[2,3-b]pyridine-3carbonyl hydrazide (IV) (0.01 mole) and 4-chlorobenzaldehyde (0.01 mole) in ethanol (25 ml) was refluxed on a water-bath for 3-4 hrs. The solvent was distilled off under reduced pressure and the residue was poured into ice-cold water to obtain the product. The compounds were filtered off, washed with cold water and dried. The crude product was recrystallized from ethanol to get a colorless crystalline solid with a yield $75 \%$ and m.p $184-186^{\circ} \mathrm{C}$. 
Its IR Spectrum $\left(\mathrm{KBr}, \mathrm{Cm}^{-1}\right)$ showed characteristic absorptions at $1690(\mathrm{C}=\mathrm{O}$, amide), $1675(\mathrm{C}=\mathrm{O}$, pyrrolo-pyridine), $1600(\mathrm{C}=\mathrm{N}), 1578 \& 1605(\mathrm{Ar}-\mathrm{C}=\mathrm{C})$.

The PMR Spectrum $\left(\mathrm{CDCl}_{3}, \square \mathrm{ppm}\right)$ of the compound showed characteristic signals at $2.62(\mathrm{~S}, 1 \mathrm{H}$, $\mathrm{CH}=\mathrm{N}$ ), 3.81 (br, s, $1 \mathrm{H}, \mathrm{NH}$ of the ring), 7.82-8.01 (m, 7H, $4 \mathrm{H}$ of $\mathrm{Ar}-\mathrm{H}+3 \mathrm{H}$ of pyrrolo-pyridine ring).

Mass Spectrum (ESI, positive) of the compound has recorded its molecular ion $\left[\mathrm{M}^{+}\right] \mathrm{at} \mathrm{m} / \mathrm{z} 298$ equal to its mass (Mol.Wt).

CHN Analyses for $\mathrm{C}_{15} \mathrm{H}_{11} \mathrm{ClN}_{4} \mathrm{O}$

Caled.: C, 60.3, H, 3.71, N, 18.76 Found: C, 60.29 H, 3.69 N, 18.71.

Based on the analytical and spectral data recorded, the compound could be characterized as pchlorophenyl(Z)-N-benzylidine-1H-pyrrolo[2,3-b]pyridine-3-carbohydrazide (Vb).

\section{Cytotoxic Activity}

Metabolic activity can be measured by adding tetrazolium salt to cells. Viable cells convert these salts to colored formazan dye that is measured spectrophotometrically. For instance, MTT assay is a nonradioactive, fast, economical and widely used to quantify cell viability and proliferation. ${ }^{10}$

Cell lines used:

- $\mathrm{MCF}-7$ (Breast Cancer)

- HT -29 (Colon Cancer)

- A 549 (Lung Cancer)

For the purpose of screening, present compounds are classified into the following groups:

Series-I:para substituted-2(IH-pyrrolo[2,3-b]pyridine-3-carbonyl-N-(p-tolyl)hydrazine carbothioamides. Series-II: (Z)-N $\mathrm{N}^{\mathrm{I}}$-benzidene-IH-pyrrolo[2,3-b]pyridine-3-carbohydrazides.

All the new azaindole derivatives (Series I to II) have been subjected to the Invitro cytotoxic tests by the appropriate standard experimental method.

\section{Series of New Azaindoles for Biological and Pharmacological Activities}

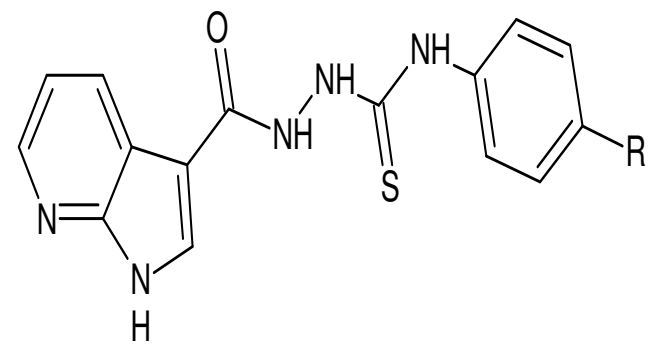

Series-I : R= H, Cl, F, OH, Br

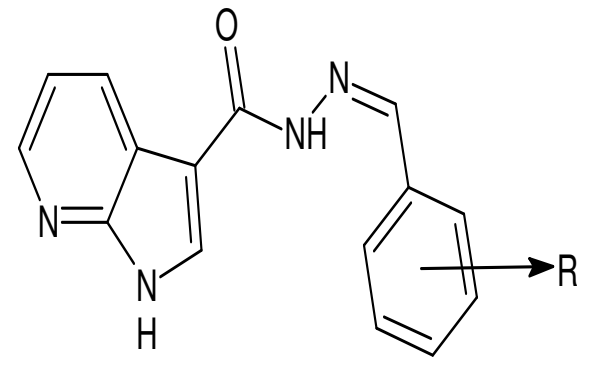

Series-II: $\mathrm{R}=\mathrm{H}, \mathrm{CH}_{3}, \mathrm{Cl}, \mathrm{F}, \mathrm{NH}_{2}, \mathrm{OH}, \mathrm{N}\left(\mathrm{CH}_{3}\right)_{2}, \mathrm{OCH}_{3}$ 
RASĀYAN $J$. Chem.

Vol. 10 | No. 4 |1316-1322 | October - December | 2017

\section{In vitro cytotoxic activity}

\section{RESULTS AND DISCUSSION}

The data pertaining to the in the vitro cytotoxic screening of new para substituted-2( $\mathrm{IH}-$ pyrrolo[2,3b]pyridine-3-carbonyl-N-(p-tolyl)hydrazine carbothioamides (Series-I) is presented in Table-1A. The test compounds were screened against three different cancer cell lines, viz.; MCF-7 (Breast Cancer), HT-9 (Colon Cancer), A 549 (Lung Cancer). Cisplatin was employed as the reference.

A perusal of Table-1A indicates clearly that two of the compounds $\mathrm{III}_{\mathrm{b}}(\mathrm{R}=\mathrm{Cl})$ and $\mathrm{III}_{\mathrm{c}}(\mathrm{R}=\mathrm{F})$ uniquely active against three types of cell lines. Whereas compound $\mathrm{III}_{\mathrm{a}}(\mathrm{R}=\mathrm{H})$ is slightly active towards MCF-7 and HT-29 but inactive against A549.

Table-1B presents the in vitro cytotoxic data of Series-II, (Z)-N'-benzidene-1H-pyrrolo[2,3-b]pyridine3-carbohydrazides against three cancer cell lines MCF-7 (Breast Cancer), HT-9 (Colon Cancer), A 549 (Lung Cancer). It reveals that only two compounds $\mathrm{V}_{\mathrm{c}}(\mathrm{R}=\mathrm{Cl}) ; \mathrm{V}_{\mathrm{d}}(\mathrm{R}=\mathrm{F})$ could inhibit all the types of cell lines studied with $\mathrm{IC}_{50}$ values $12.9,10.2$ and 21.6 respectively. The activity of these two compounds is comparable with that of standard Cisplatin. However, all the synthesized compounds except $V_{c} \& V_{d}$ in the Series-II possess cytotoxic activity but not comparable with the reference standard Cisplatin.

Table-1A: In vitro cytotoxic activity of Para substituted-2-(H-pyrrolo[2,3-b]pyridine-3-carbonyl-N-(ptolyl)hydrazine carbothioamide [Series-I].

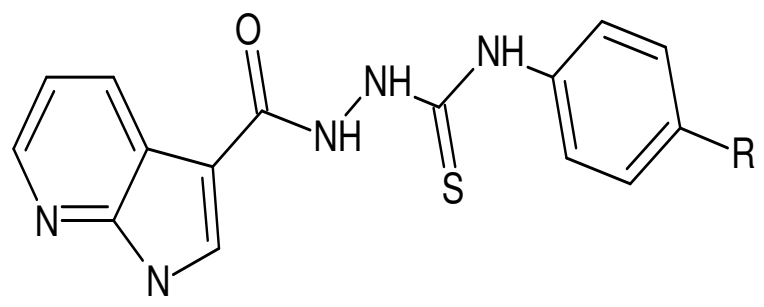

$\mathrm{H}$

\begin{tabular}{c|c|c|c|c}
\hline \multirow{2}{*}{ Compound } & \multirow{2}{*}{$\mathrm{R}$} & \multicolumn{3}{|c}{$\mathrm{IC}_{50}(\mu \mathrm{m})$} \\
\cline { 3 - 5 } & & $\mathrm{MCF}-7$ & $\mathrm{HT}-29$ & $\mathrm{~A} \mathrm{549}$ \\
\hline IIIa & $\mathrm{H}$ & 171.5 & 88.2 & NA \\
\hline IIIb & $\mathrm{Cl}$ & 10.2 & 12.7 & 30.2 \\
\hline IIIc & $\mathrm{F}$ & 15.8 & 28.3 & 35.5 \\
\hline IIId & $\mathrm{OH}$ & 25.6 & 68.7 & 59.6 \\
\hline IIIe & $\mathrm{Br}$ & 70.4 & 6.56 & 14.31 \\
\hline Cisplatin & -- & 8.61 & & \\
\hline
\end{tabular}

(NA: No Activity)

Table-1B: In vitro cytotoxic activity of (Z)-N'-benzylidene-IHpyrrolo[2,3-b]pyridine-3- carbohydrazides [Series-II].

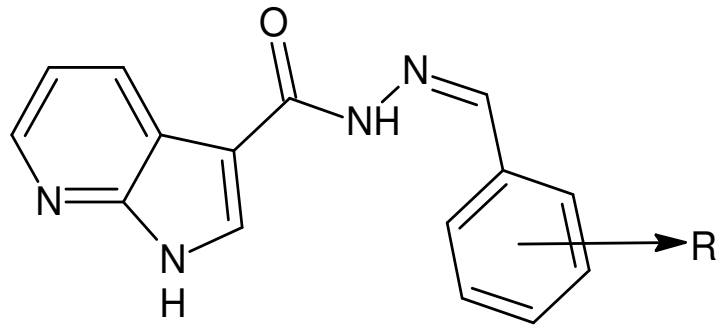

\begin{tabular}{c|c|c|c|c}
\hline \multirow{2}{*}{ Compound } & \multirow{2}{*}{$\mathrm{R}$} & \multicolumn{3}{|c}{$\mathrm{IC}_{50}(\mu \mathrm{m})$} \\
\cline { 3 - 5 } & & $\mathrm{MCF}-7$ & $\mathrm{HT}-29$ & $\mathrm{~A} \mathrm{549}$ \\
\hline $\mathrm{Va}$ & $\mathrm{H}$ & 125.9 & 40.7 & 49.37 \\
\hline $\mathrm{Vb}$ & $\mathrm{CH}_{3}$ & 70.5 & 35.6 & 38.4 \\
\hline
\end{tabular}


RASĀYAN J. Chem.

Vol. 10 | No. 4 |1316-1322 | October - December | 2017

\begin{tabular}{c|c|c|c|c}
\hline $\mathrm{Vc}$ & $\mathrm{Cl}$ & 12.9 & 10.2 & 21.6 \\
\hline $\mathrm{Vd}$ & $\mathrm{F}$ & 10.5 & 9.2 & 19.5 \\
\hline $\mathrm{Ve}$ & $\mathrm{NH}_{2}$ & 80.6 & 50.4 & 49.6 \\
\hline $\mathrm{Vf}$ & $\mathrm{OH}$ & 38.4 & 33.7 & 50.1 \\
\hline $\mathrm{Vg}$ & $\mathrm{N}\left(\mathrm{CH}_{3}\right)_{2}$ & 40.6 & 35.6 & 55.7 \\
\hline $\mathrm{Vh}$ & $\mathrm{OCH}_{3}$ & 80.5 & 60.4 & 70.9 \\
\hline Cisplatin & -- & 8.61 & 6.56 & 14.31 \\
\hline
\end{tabular}

CONCLUSION

Azaindoles are an important class of nitrogen-containing heterocyclics and were identified as the most active and potent classes of compounds with a wide range of biological and pharmacological activities. They were extensively used as pharmaceuticals. Although the number of drugs is available in the market even though the search for new molecules is ever demanding.

Finally, the Azaindole derivatives screened for their possible Invitro Cytotoxic activity. Some of the molecules exhibited very good potency when compared with respective standards.

The approach is very challenging and was found difficult to get a molecule with potency. Even though, the present molecules were provided novel leads against Cancer and also insights into structural features required to be considered while designing the molecules with Azaindole core structures for cytotoxic studies.

\section{REFERENCES}

1. B.G. Jackson, Mechanism-based target identification and drug discovery in cancer research. Science, 2000, 287-1969.

2. M. Dikmen, N. Ozturk, Y. Ozturk, J. Med. Food., 14, 1638 (2011)

3. C. Lengauer, K.W. Kinzler, B. Vogelstein, Nature, 396, 643 (1988).

4. E.A. Nigg, Nat. Rev. Mol. Cell Biol, 2(1), 21(2001).

5. N. Sagar, J. Venkateshawar Rao, AKS Bhujanga Rao, Asian Journal of Pharmaceutical and Clinical Research, 5(1), 89 (2012).

6. A.L. EL-SHENAMY, Chem. Pap., 58(3), 205(2004)

7. F.K. Mohammed, H.M. Bakeer and M.A. EL-Hashash, Asian J. Chem., 21(7), 5004 (2009).

8. A.H. EL-Marsy, H.H. Kahmy and S. Asdel-Wahead, Molecules, 5, 1429(2000).

9. H.G. Boncorso, A. D. Wastowski, N. Zanatta, Journal of Flourine Chemistry, 92, 23 (1998).

10. T. Mosmann, J. Immunol. Methods, 65, 55(1983).

[RJC-1914/2017] 